Western University

Scholarship@Western

7-3-2018

\title{
Social Capital in Higher Education Partnerships: A Case Study of the Canada-Cuba University Partnership
}

Marianne A. Larsen

Western University, mlarsen@uwo.ca

Clara I. Tascón

Western University

Follow this and additional works at: https://ir.lib.uwo.ca/edupub

Part of the Education Commons

Citation of this paper:

Larsen, M. A. \& Tascon, C. (2018). Social Capital in Higher Education Partnerships: A Case Study of the Canada-Cuba University Partnership. Higher Education Policy, pp. 1-21. 


\title{
Social Capital in Higher Education Partnerships: A Case Study of the Canada-Cuba University Partnership ${ }^{1}$
}

Marianne A. Larsen and Clara I. Tascón

Faculty of Education, Western University, 1137 Western Road, London, ON N6A 1G7, Canada.

E-mails: mlarsen@uwo.ca; ctascond@uwo.ca

\begin{abstract}
This article reports on the findings of a case study about the Canada-Cuba University Partnership (CCUP), a teaching, research and service partnership between individuals associated with a Canadian and Cuban University. The research question guiding the study was: "How do the relationships among individuals in the CCUP shape the partnership?" Our review of existing literature on higher education partnerships reveals the lack of literature focusing on the relationships among individual partnership members. Our study is framed by social capital as our theoretical approach and social network analysis as our methodological approach. These approaches enable us to map out the connections between and among individuals and show the importance of their relationships. We analyze the partnership focusing on social capital, highlighting the mutually-beneficial activities and the role of central actors in the network who contributed to the formation of the partnership and the long-lasting relationships among academics in both countries. Relationships in the CCUP are characterized by mutuality, solidarity, strong and thick ties. The argument we advance is that understanding the collaborative relationships among members of higher education partnerships and the productive capacities of those relationships through the enactment of social capital provides insights into how sustainable and successful partnerships work.
\end{abstract}

\section{Introduction}

In today's global knowledge economy, international scholarly exchanges and research collaborations are considered necessary components of a successful academic career. As a report from Association of Universities and Colleges of Canada (2005) explains, "being internationally competitive means being internationally collaborative" (p. 14). To this end, higher education

\footnotetext{
${ }^{1}$ Cite as: Larsen, M. A. \& Tascon, C. (2018). Social Capital in Higher Education Partnerships: A Case Study of the Canada-Cuba University Partnership. Higher Education Policy, pp. 1-21.
} 
institutions (HEIs), governments, regional associations and agencies now promote international higher education partnerships. Global and national rankings of universities are central to these trends. The World University Rankings, for example, now includes 'International Outlook' among its criteria for ranking universities with one of the key indicators being 'international collaboration' (Times Higher Education, 2016). Consequently, there has been an increase in international research collaborations and partnerships, many which cross North-South divides (Kot, 2016; Singh, 2010). Indeed, as Sutton, Egginton and Favela (2012) assert, institutional partnerships have emerged as the "defining characteristic of academic internationalization" over the past two decades (147).

There is a growing body of literature on international research partnerships on the role of higher HEIs involved in partnerships (e.g. Kim \& Celis, 2016). However, less is known about the collaborative interactions amongst individuals which shape international partnerships over time. Understanding the relationships among members of higher education partnerships and the productive capacities of those relationships through the enactment of social capital can provide insights into how strong, sustainable and successful partnerships work (Abbasi, Wigand, \& Hossain, 2014; Bordogna, 2018; Ferrier \& Haxton, 2014; Kinser \& Green, 2009). This case study about the Canada-Cuba University Partnership (CCUP), a partnership between individuals associated with the Canadian University $(\mathrm{CaU})$ and the Cuban University $(\mathrm{CuU})$, addresses that issue. ${ }^{2}$ The origins of the partnership date back to discussions and relationship building among individuals from both universities almost 20 years ago. In 2002, official institutional agreements

\footnotetext{
${ }^{2}$ Pseudonyms are used throughout the paper for the universities and all participants in the study.
} 
were signed between members of both HEIs to formalize the partnership. At that point, the partnership entailed a wide range of cooperative activities across four disciplines: education, foreign languages and applied linguistics, social work, business and accounting. Faculty members from 8 different faculties (4 at each university) have been involved in various teaching, research and service collaborations. The research question guiding the study was: "How do the relationships among individuals in the CCUP shape the partnership?" Our 2 sub-questions were: "What was the role of relationship building in the establishment of the CCUP?" and "How, if at all, has the social capital embedded in CCUP relationships enabled participants to pursue shared goals?"

In this paper, we first provide a brief overview of some existing literature on $\mathrm{HE}$ partnerships. We outline the theoretical framework, social capital, which guides our study, and the research methods and methodology of our study. Given our interest in the connections between individual members in the partnership, we use social network analysis (SNA) as our methodological approach. Together, social capital theory and SNA enable us to map out the connections between and among individuals and show the importance of their relationships. In our findings section, we review the relationships at the core of the establishment of the CCUP and the reciprocal outcomes these relationships have brought to scholars in both universities. In the final section, we analyze the partnership focusing on the concept of social capital, highlighting the mutually-beneficial activities and the role of central actors in the network who contributed to the formation of the partnership and the long-lasting relationships among academics in both countries. 


\section{Literature Review}

Following Tedrow and Mabokela (2007), we understand HE partnerships to be "formally developed relationships between institutions where the participating partners derive mutual benefit from the involvement" (159-160). Partnerships can focus on exchange, research, and/or service and be between HEIs, between a HEI and government or non-profit agency; or between a HEI and a private partner (Sutton, Egginton \& Favela, 2012). Our study focuses on a teaching, research, exchange and service partnership between individuals based in two HEIs.

Here we summarize key themes emerging in the research literature on HE partnerships related to the focus areas of our study (i.e. North-South partnerships, benefits and challenges of partnerships, social capital and social networks in partnerships). There is a growing body of literature on the benefits and value of HE partnerships (Kinser \& Green, 2009). With respect to North-South partnerships, there is research on capacity building (Chapman, Pekol \& Wilson, 2014; Koehn \& Obamba, 2012; Obamba \& Mwema, 2009) and the financial benefits of international partnerships for Global South institutions (Morfit, Gore \& Akridge, 2009; Teferra, 2009). Partnerships are also viewed as having the potential to help revitalize the role of Global South universities and local, Indigenous knowledge systems (Kot, 2016; Teferra, 2009).

Others, however, have critiqued the extent to which international partnerships build capacity and strength within Global South institutions over the long run. Overall, the bulk of literature on international $\mathrm{HE}$ partnerships critiques the purpose, functions and consequences of partnerships for Global South HEIs. Dependency theory scholars have long critiqued unequal power relations stemming from international partnerships, which privilege the needs, values and 
knowledge of the North over those from the South and reinforce inequalities and dependencies (e.g. Carnoy, 1974). Building on this research, more recent scholars have critiqued the ways in which HE partnerships continue to intensify the hegemony of Western knowledge, cultural values and languages at the expense of local cultural norms, language and knowledges (Assié-Lumumba, 2006; Jowi, 2009; Leng, 2016; Obamba \& Mwema 2009).

Given our theoretical and methodological frameworks outlined below, we briefly review research on academic partnerships and collaboration that draw upon social network analysis and/or the concept of social capital. Wagner and Leydesdorff (2006) analyzed international research collaboration within a set of wide-scale studies. They mapped global co-authorship relations suggesting that international scientific networks are complex, self-organizing networks based on preferential attachment. Abbasi, Wigand, and Hossain's (2014) study of scholarly co-authorships demonstrates the influence of social capital within the context of academic collaboration and suggests that the collaborative process involves social capital embedded within relationships and network structures among co-authors.

There are only a handful of studies that deploy SNA to analyze HE partnerships (e.g. Kim \& Celis, 2016; Long, Cunningham, Carswell \& Braithwaite, 2014; Yeh \& Chang, 2016). For example, a recent study by Kim and Celis (2016) used SNA to study global partnerships of MBA programs. They mapped the connections between international partnerships amongst a set of highly-ranked MBA programs creating a network structure of programs and institutions, not individuals (as we have done so in our study). Finally, it is worth noting that empirical case studies, especially those focusing on individual relationships, of international HE partnerships remain 
scarce (Ferrier-Kerr \& Haxton, 2014; Kot, 2016; Leng \& Pan, 2013), providing further justification for our study.

\section{Research Methods: Case Study}

Case study is a qualitative methodological approach aimed at gathering in-depth and comprehensive information about the particularity and complexity of a case or what Stake (1995) calls a bounded or integrated system. For this study, our case is the CCUP, a case of an international HE partnership. The CCUP was chosen for this study given its grassroots, mutuallybeneficial origins, long-term duration, and the academic interconnections among individuals involved in the partnership. Data collection included documentary analysis and semi-structured interviews. Documents included the formal partnerships agreements between the two universities, a draft history of the partnership written by one of the Canadian members, as well as conference materials from one participant about the partnership.

Participants had all been involved in the CCUP for at least 2 years, belonged to one of the two universities engaged in the partnership, and were willing to participate in a semi-structured interview. Based on the involvement of one of the authors with the partnership, key people were contacted by email with a letter of information and consent form. Using snowball sampling procedures, we asked these key individuals to provide us with the names of others involved in the partnership. We then contacted those individuals to participate in our study. Semi-structured interviews were carried out with 24 participants in English and Spanish according to their preference. Interviews, which ranged from 15-60 minutes, took place face-to-face in each country, Skype or by telephone. The interviews, which probed participants about the origins and activities 
of the partnership, as well as their own personal involvement with the CCUP, were recorded and transcribed. Tables 1 and 2 provide an overview of the participants (interviewees) in our study and other actors connected within the network.

Table 1. Canada Participants and other Network's Actors ${ }^{3}$

\begin{tabular}{|c|c|c|}
\hline Participant & Acronym/Code & Position \\
\hline Sandra Martins & SMCan & Professor, Faculty of Education \\
\hline Julia Kern & JKCan & Grad Student, Dept. of Modern Languages \& Literature \\
\hline Jane Buitrago & JBCan & $\begin{array}{l}\text { Professor/Chair, Dept. of Linguistics/Modern Languages and } \\
\text { Literature }\end{array}$ \\
\hline Alicia Gómez & AGCan & Lecturer, Dept. of Modern Languages \& Literature \\
\hline Michael Kenneth & MKCan & Coordinator, Dept. of Modern Languages \& Literature \\
\hline Joe Torrino & JTCan & Associate Professor, Dept. of French Studies \\
\hline Rose Castor & RCCan & Professor/Former Associate Dean, Faculty of Education \\
\hline Jim Dokester & JDCan & Vice-Provost Academics \\
\hline Cliff Toor & CTCan & Retired Professor/Director, Dept. of French Studies, \\
\hline Frank Kellen & FKCan & Director of International Research \\
\hline Donald Horton & DHCan & Professor, Dept. of French Studies, \\
\hline Bob Heath & BHCan & Associate Professor, Dept. of Sociology \\
\hline No Interview & TAsCan & Teaching Assistants \\
\hline No Interview & CanSs & Students, Study Abroad and ISL Programs \\
\hline $\begin{array}{l}\text { Michelle Leluk } \\
\text { No Interview }\end{array}$ & MLCan & Professor/Chair, Faculty of Education \\
\hline No Interview & SsCanColl & Students, Canada \\
\hline
\end{tabular}

${ }^{3}$ All names of participants are pseudonyms. The acronym code can be interpreted as follows: the first two letters are the initials of the participant (e.g. SM), followed by 'Can' indicating a Canadian member of the partnership, and 'Cub' indicating a Cuban member of the partnership. 
\begin{tabular}{l|l|l} 
No Interview & PresidentCanU & President, CaU
\end{tabular}

Table 2. Cuba Participants and other Network's Actors

\begin{tabular}{|c|c|c|}
\hline Participant & Acronym/Code & Position \\
\hline Igor Forero & IFCub & Director, Cuban Institute of Friendship \\
\hline Bertha Gómez & BGCub & Professors, Coordinator Spanish Program \\
\hline Vera Pinero & VPCub & Professor, CuU (Head of the Department of Languages) \\
\hline Lucas Martínez & LMCub & Director, Office of International Relations \\
\hline Betina López & BLCub & Professor, Latin American Literature \\
\hline Yselta Hernandez & YHCub & Associate Dean and Professor, Spanish Program \\
\hline Yolanda Bermeo & YBCub & Professor, Spanish \\
\hline Hugo Lozano & HLCub & Owner, Particular House \\
\hline Tulia Cortez & TCCub & Owner, Particular House \\
\hline Alma Cubillos & ACCub & Director, Disabilities Institute \\
\hline Rosa Gutiérrez & RGCub & Director, Language Department \\
\hline Carla Gómez & CGCub & Professor, Spanish and Cuban Culture \\
\hline $\begin{array}{l}\text { Rosalba Suárez } \\
\text { No Interview }\end{array}$ & RSCub & Professor, French Department \\
\hline $\begin{array}{l}\text { Jose Llanos } \\
\text { No Interview }\end{array}$ & JLCub & Doctoral Student \\
\hline $\begin{array}{l}\text { Jorge Fuentes } \\
\text { No Interview }\end{array}$ & JF Cub & Professor, English Department \\
\hline No Interview & $\mathrm{SsCub}$ & Students \\
\hline No Interview & FPsCub & French Professors \\
\hline No Interview & PresidentCubU & President, CuU \\
\hline
\end{tabular}




\section{Theoretical Framework: Social Capital}

Our theoretical framework, social capital, is based on the ideas of Bourdieu (1986), Coleman (1988) and Putnam (1995). Bourdieu argued that the social world cannot be understood without taking into account capital in all its forms, economic, cultural and social. The amount of cultural and economic capital influences the volume of social capital an individual may possess. Social capital refers to the potential or actual resources connected to membership in social networks. It is characterized by mutual recognition, common norms, and trust. Social capital is created through and exists within durable networks, relationships and exchanges. Bourdieu (1986) explains that "[t]he network of relationships is the product of investment strategies, individual or collective, consciously or unconsciously aimed at establishing or reproducing social relationships that are directly usable in the short or long term" (52). The volume of social capital a person can possess depends upon the size of the connection network mobilized and the amount and quality of economic, cultural or symbolic capital possessed by the individual and/or by those to whom s/he is connected. And finally, social capital facilitates the actions of members within the group/network and enables the production of further economic, cultural and social capital.

Like Bourdieu, Coleman used the concept of social capital to examine the social contexts of education, particularly with respect to social class and educational outcomes. Coleman (1988) argued that social capital is "a variety of different entities, with two elements in common: they all consist of some aspect of social structures, and they facilitate certain actions of actors-whether persons or corporate actors - within the structure" (1998). For Bourdieu, social capital is a personal asset that provides tangible advantages to those individuals, families or groups that are 
connected to one another. However, Coleman's definition alerts us to the idea that social capital exists in relationships between individuals, not (as Bourdieu argues) in individuals themselves. Similarly, Putnam (1995) used the term to explain differences in Italian and US civic and social engagement, defining it as those "features of social life — networks, norms and trust — that enable participants to act together more effectively to pursue shared objectives" (665). Our framework is more closely aligned then with the work of Coleman (1988) and Putnam (1995) who understand social capital as social networks of trust, solidarity and reciprocity. For them (and for us) it is a community asset, and by implication assumes the existence of a homogeneous community with common interests and shared values. Bringing together all three definitions, for the purposes of our study we consider social capital stemming from a social network of strong and stable relationships, characterized by common values, trust, reciprocity and solidarity, that enable the production of mutually beneficial outcomes.

\section{Methodological Approach: Social Network Analysis (SNA)}

SNA is a methodological approach that helps to map interconnections between members of a network. A network is understood to be as a set of individuals or group, 'points' or 'nodes', interconnected by 'lines' or 'ties', which show the relations that connect each point (Borgatti \& Halgin, 2011; Mützel, 2009; Wagner \& Leydesdorff, 2005). In this study we conceptualize the CCUP, a higher education partnership, as a network. The difference between data analysis and social network analysis is that SNA focuses on the ties or connections between the nodes, rather than the members/nodes themselves (Pinheiro, 2011). Using SNA as a methodological approach 
requires identifying the members (nodes) of the network, defining the roles of the nodes, what counts as a link, and defining the boundaries of the network (Borgatti \& Halgin, 2011; Pinheiro, 2011).

In our study, the nodes represent the individuals who have established and nurtured the partnership. The links are relationships and collaborative interconnections through which individuals engaged in activities such as teaching, research and service within the CCUP. Links then constitute channels of communication where social capital flows between nodes/individuals. The width of a link in the CCUP network's visual representation shows the strength, density, of the connections between the nodes/individuals. We measured density by the amount of ties/connections each node has within the network. The concept of node's betweenness centrality in communication is that a point/node "falls on the shortest path between pairs of other [nodes]" (Freeman, 1977, p. 35). Thus, high density of connections between certain individuals/nodes determines their central position within the network (Scott \& Carrington, 2011). Our visual representation of the nodes/individuals and their multiple connections/links in the partnership illustrates the network's social capital flow through links' density, nodes' betweenness centrality and other nodes' positions within the network, topics taken up in our discussion below. (See Figure 1.)

Through our interviews, we generated a list of the names of the network members. Each member was given a pseudonym (e.g. Vera Pinero) and an abbreviation based on the initials of the individual and university where they were based (e.g. VPCub or RCCan). Our interviews also provided qualitative data about each participant's ideas and descriptions about ties/relationships, 
networks events, and activities in the partnership. As Crossley et al., (2015) emphasize, qualitative information provides a member's "account of the network from their point of view...[and] what ties 'mean' to network members" (106). In this way, participants in our study helped us understand the dynamics of the network. In SNA, the information gathered is incorporated into matrices using specialized software to create a visualization of the network. In this study, we used NodeXL to represent the network of the CCUP partnership. Using our data, we input the members of the partnership into NodeXL as nodes in connection to other nodes. We mapped the ties/relationships of the members involved in the process of creation, establishment, and development of the CCUP partnership. Then, based on our interview data, we assigned each node a shape that represents the nodes' role within the network. Each node was also assigned a number in relation to his/her influence or leadership in the network, which determined their node's size. Bigger nodes represent the most influential actors. Nodes occupy different positions in a network according to their roles, which result in multiple nodes that are not always directly tied. Thus, we identified "the influential nodes, the leaders, the followers, and the isolated...ones" (Pinheiro, 2011, 13). We also assigned a number to the width of the links representing the strength of the connections between the different actors. Thus, thicker links depict the stronger connections amongst individuals within the partnership.

In Figure 1 the high density of connections of JTCan and VPCub with other individuals of the partnership shows their central position within the network. These individuals are represented by larger dark spheres in the figure. We can also observe the close position of DHCan and RCCan (medium black diamonds), who have significant density of connections within the partnership, 
since they play important roles supporting the establishment and work of the partnership. SMCan (smaller black diamond) also played an important role while collaborating with VPCub's doctoral research. The position of LMCub (medium black square) close to VPCub represents his connectivity and permanent support in the development of the partnership. Other medium blacksquares (i.e. FKCan, JDCan, President CanU, and President CubU) depict actors that have provided administrative support signing the CCUP agreements (See Tables 1 and 2).

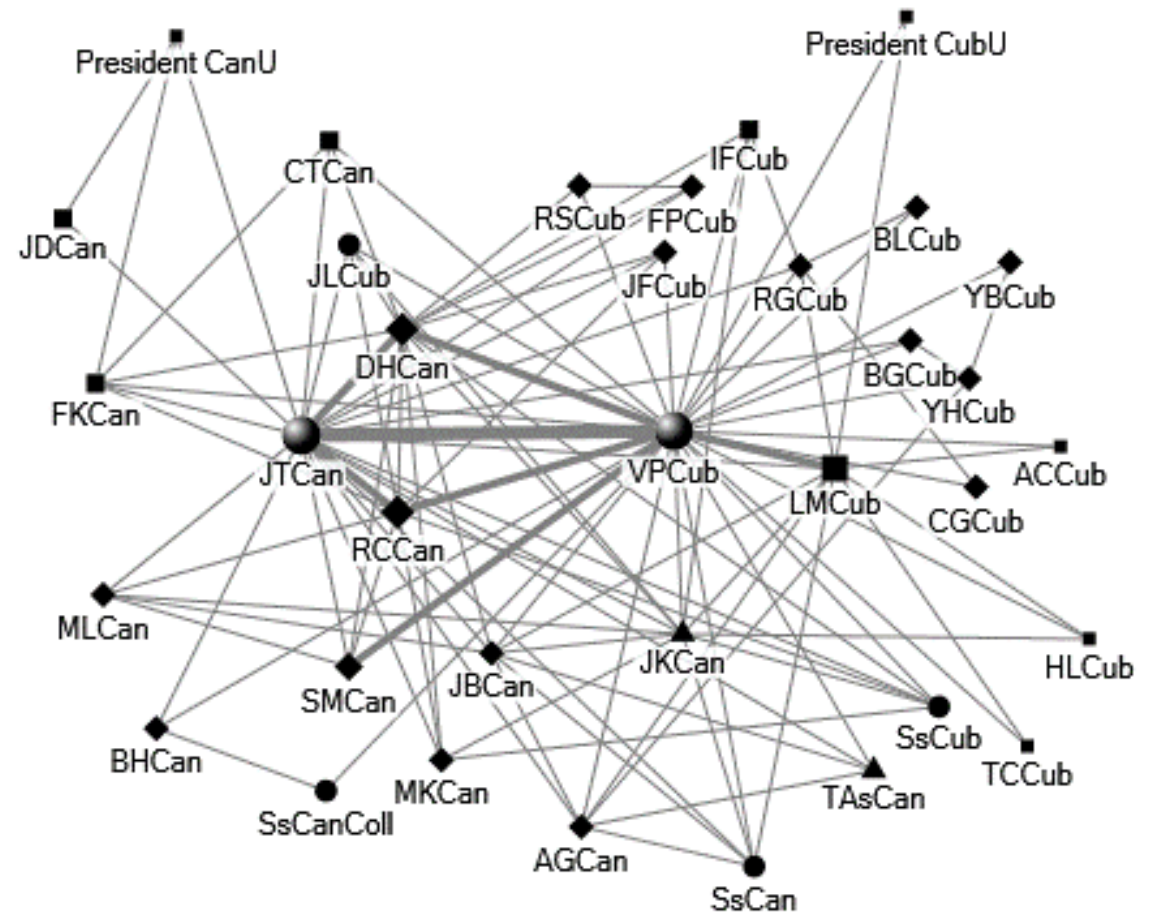

\section{Figure 1. Connections between nodes in the CCUP network}

The density of connections (relationships) between individuals determines the nodes' position, betweenness, centrality, shape, and size within the network according to their roles in the CCUP.

Larger dark spheres $=$ Central actors - Champions

Diamonds $=$ Professors

Squares $=$ Administrative staff

Triangle $=$ Teaching Assistants

Circle $=$ Students 


\section{Findings}

\section{Establishment of the CCUP}

Our data demonstrates the relationship-based foundation of the CCUP, which began serendipitously in 1999 when Cliff Toor (CTCan), Director of the CaU French Studies Department was vacationing at a Cuban resort where he met a student from the $\mathrm{CuU}$ Languages Department translator/interpreter training program. The student introduced him to Pinero (VPCub), head of the CuU Languages Department. Conversations between Toor and Pinero continued over the following year as Toor travelled back to Cuba and met with the Dean and Vice Dean of the CuU Faculty of Humanities to discuss common interests and possible collaborative projects. During this time, Toor also talked with colleagues at the CaU Department of French Studies about the work being done in language teaching at $\mathrm{CuU}$. Two professors, Joe Torrino and Donald Horton, were particularly interested in this work. Both had long-standing interest in Spanish and Hispanic studies, as well as Cuban society and history. These early discussions in Canada between Toor, Torrino and Horton, along with Toor's discussions in Cuba with Pinero, the Dean and Vice-Dean of the CuU Faculty of Humanities formed the early partnership relationships,

In June 2001, Horton and Torrino travelled to Cuba to attend a conference, which led to further discussions about potential areas for collaboration and how to move the partnership forward. Simultaneously, the $\mathrm{CuU}$ was undergoing a process to have their French program accredited by the Cuban Ministry of Education, which necessitated having courses in linguistics. "Accidentally" as Horton explained, both he and Torrino were linguists, and they could support the $\mathrm{CuU}$ in completing the requirements for program accreditation. In the summer of 2001, Pinero 
went to Canada as a visiting scholar to work on her dissertation. Pinero was supported, in her research on language acquisition, by Sandra Martins (SMCan) at the Faculty of Education. During that summer, Pinero had many conversations with the Associate Dean of the Faculty of Education, Rose Castor (RCCan), about establishing a Canadian Studies program at the CuU Faculty of Humanities. ${ }^{4}$ They collaborated and submitted a grant application to the Canadian government, which was resulted in the establishment of a Canadian Studies program at CuU in 2002.

During that same summer, Pinero, keen to develop the partnership, spoke with people at $\mathrm{CaU}$ about opportunities for further collaboration. These included professors from the French Studies Department, Faculty of Education, as well as Frank Kellen (FKCan), Director of CaU International Research. By then, Torrino and Horton had already initiated conversations with Kellen about the potential of forming a formal partnership with CuU. The CaU President was also supportive of the partnership given his own personal interest in foreign languages. All agreed that this partnership should be mutually beneficial to individuals in both institutions. As a result of these discussions, representatives at the $\mathrm{CuU}$ and $\mathrm{CaU}$ signed two letters of intent in June and October 2001, outlining the cooperative initiatives to be undertaken by the institutions. In April 2002, two years after that initial "coincidental” (DHCan, 2015, personal communication) meeting at the resort and numerous, informal conversations and relationship-building initiatives between CCUP members, the first official, institutional agreement between the $\mathrm{CuU}$ and $\mathrm{CaU}$ was signed.

\footnotetext{
${ }^{4}$ Since the late 1960s, the Canadian government had been providing grants to Canadian scholars to develop Canadian studies programs abroad. By the 1990s the focus of the program shifted to supporting grants for foreign academics to develop their Canadian studies programs. Grants for these programs were cancelled in 2012.
} 
The broad agreement described cooperative initiatives across four areas of common concern: teaching foreign languages and linguistics, education/pedagogy, social work, and business.

\section{Shared Goals: mutually beneficial activities}

Our data reveals the shared goals and mutually beneficial nature of the partnership, stemming from the social capital inhering in the relationships between members. Unlike other HE partnerships, the CCUP is constituted by activities overlapping teaching, research and service dimensions. Research collaborations between Cuban and Canadian partners cross various, shared fields including business, education, engineering, and second language acquisition/linguistics. Torrino and Horton $(\mathrm{CaU})$, for example, joined with professors Fuentes and Gómez $(\mathrm{CuU})$ to develop a project of sociolinguistic research on Cuban Spanish, which received financial support from $\mathrm{CaU}$. Commenting on recent discussions between partner members regarding collaborative engineering and economics research projects, JDCan noted, "any time you have these kinds of partnerships there are very much mutual benefits because ...in the exchange of ideas from, in particularly different cultural contexts ...helps to identify issues that would not occur to us otherwise" (JDCan, 2015, personal communication).

The annual conference in Cuba, which focuses on modern languages and Canadian Studies has remained one of the core features of the partnership, a recognition that face-to-face encounters are crucial to maintaining the integrity of the partnership. As Torrino noted, the conference "is a means of connecting people...there has been all kinds of collaborations [and] lots of cooperation" that has taken place with respect to the annual conference. Both faculty and graduate students from 
Cuba and Canada attend the conference. Bob Heath (BHCan), in reflecting upon his experiences attending the Cuban conference, noted how discussions with conference participants stimulated his thinking around critical issues. He concluded that the conference was "a very good academic exercise" and exchange, and that he found it a "very satisfying relationship and a very stimulating one" (BHCan, 2015, personal communication).

Cross-border teaching is another mutually-beneficial dimension of the partnership. Canadian members of the partnership have travelled to Cuba to teach 'pre-conference courses' at the annual conference, and in the French and Canadian Studies programs. DHCan worked with Rosalba Suárez $(\mathrm{CuU})$ to teach her and other professors French linguistics and to develop the $\mathrm{CuU}$ French program. Pinero during her visits to Canada has delivered numerous lectures on Cuban society, education, language learning, etc. Business management teaching practices have also been shared between individuals in the CCUP. CuU instructors, for instance, translated business management teaching materials to be shared between the two universities; and CaU MBA students spent a month at $\mathrm{CuU}$ exchanging ideas with their Cuban counterparts about teaching business management. Canadian partners commented on the value of learning from their Cuban counterparts about language teaching. SMCan, a linguist, concluded that the CuU language department was an "absolutely fantastic teaching organization" with "good methods" with their language courses. FKCan noted that the partnership has been "very good for the university because the language teachers at $[\mathrm{CaU}]$ have been exposed to very effective language teaching in Cuba." And RCCan remarked on the high levels of expertise and proficiency with the English language 
amongst the $\mathrm{CuU}$ students she met, concluding that their language skills were "a tribute to the language teaching that Cuba does."

Students have also been involved in academic and research exchanges. CaU students have travelled to $\mathrm{CuU}$ to take courses in Spanish language and culture since 2002. Many CaU students have also attended the annual Cuban conference and presented papers there. In 2012, an international service learning (ISL) program was established within the CaU languages department to facilitate learning Spanish, as well as learning "about Cuban institutions, and having some contacts with Cubans and Cuban society" (JTCan, 2015, personal communication). Unlike many North-South partnerships, we see in the CCUP the movement of scholars, faculty and students, from the South (Cuba) to the North (Canada). For instance, the Cuban student, José Llanos (JLCub) went to $\mathrm{CaU}$ for his $\mathrm{PhD}$ and then won a very prestigious scholarship to continue his studies at the post-doctoral level. Torrino claimed that Llanos was a "real success history of this partnership" (JTCan, 2015, personal communication).

And finally, there have been financial benefits to the partnership. Canadian partners when travelling to Cuba have brought academic books, computer equipment, and other educational resources, which are difficult for the Cuban partners to obtain. Indeed, as Horton told us, the mere act of travelling to and staying in Cuba made a "valuable economic contribution" (DHCan, 2015, personal communication). Furthermore, registration fees for Canadian participants in the annual conference in Cuba, make it possible for Cuban participants to attend, who might otherwise be unable to given the low value of the local Cuban peso. To conclude, we quote from Martins who noted that the partnership represented the best way to engage in internationalization because as "a 
mutual kind of thing, you are exchanging ideas [and] you are exchanging resources" (SMCan, 2015, personal communication).

\section{Relationships at the core of the partnership}

Our findings show that one cannot understand how internationalization is 'engaged' without paying attention to the micro-level connections between individual actors involved in activities such as international partnerships. Almost all of those we interviewed spoke about the close relationships and friendships that developed through the partnership. As noted above, informal conversations between Canadian and Cuban academics developed initial connections that became meaningful relationships over time. As Torrino mentioned, "personal connections with shared academic interest and commitment" have characterized the partnership. He continued, "research collaborations, scholarly collaborations, as well as personal friendship and international connections developed out of it" (JTCan, 2015, personal communication). Horton also told us that the partnership "emerged from human contact...and kindness" (DHCan, 2015, personal communication) as he explained that he had the opportunity to establish close relationships with Cuban professors' families at the time he was teaching French linguistics during his sabbatical in Cuba. In this sense, professors, students, and administrative staff from both universities shared cultural and social activities and events, which strengthened their understanding of one another and their relationships.

Canadian students who participated in diverse cultural and social activities within Cuba found them to be a "completely different [and] very transformative experience" (JBCan, 2015, 
personal communication). The relationships that began in Cuba evolved into close and long-lasting friendships between the Cubans and Canadian students. As CaU students were hosted in Cuban families, they not only practiced Spanish, but also developed affective ties that were maintained after their program ended. As Martínez emphasized, "there are many students who send postal cards with greetings for Christmas, New Year's Eve, birthdays to the families and people who they shared with during the program" (LMCub, 2015, personal communication). In the same way, Cuban professors and students in their visits to Canada are hosted by Canadian academics. Together they participated in shared research/academic, social-cultural activities that strengthened their friendship and familiarity with Canadian culture. As FKCan explained, "the friendships with VPCub and her husband are very precious to me. They are lovely people and [my wife and I] will maintain those friendships to the end of our days" (FKCan, 2015, personal communication).

Trust building has been one on the main components of the strong relationships amongst colleagues in the partnership. It enabled academics to be engaged with other colleagues and people in the community in Cuba and in Canada. For instance, official permission from Cuban organizations was required for Canadian students to participate in social work and ISL there. Due to the relationships between Cubans and Canadians in the network, permission was obtained. As JKCan told us, at the beginning of the ISL program, that IFCub, the director of that organization, said, "because you are friend with VPCub, I can trust you and you can go ahead [with the program] for the following year" (JKCan, 2015, personal communication). And she continued, "for me that was evidence right there that this friendship that I had for five years with [VPCub] happened to be 
the connection that I needed to get this permission that may had taken two or three years" (JKCan, 2015, personal communication).

Finally, strong relationships amongst $\mathrm{CaU}$ and $\mathrm{CuU}$ academics contributed to expanding the network of scholars. These interconnections have nurtured significant discussion in the area of linguistics, second language and Hispanic studies, as well as on social and human rights issues. As Heath emphasized, "I value the exchanges that we have, that comes out of this partnership, it is really been helpful for me and thinking further about some of the issues that I deal with here in a Canadian university, and it is very helpful to be able to talk with other people from other parts of the world that often are struggling with similarly issues" (BHCan, 2015, personal communication). Participants mentioned instances of institutional, academic and family hospitality, which enabled to them to not only to access resources, but more importantly, to deepen relationships with one another. It is this sense, as Horton explained, that "education is a form of human contact... one can get a book or computer support, but what remains and lasts for me are the lessons we receive and share with people" (DHCan, 2015, personal communication).

\section{Discussion}

\section{Social Capital and the establishment of the CCUP}

The SNA approach deployed in this study has allowed us to see how "individuals are embedded in thick webs of social relations and interactions" (Borgatti, Mehra, Brass \& Labianca, 2009, 892). To 'see' and make sense of these interconnections we constructed an account of the CCUP relationships developed between 1999-2002. Contrary to most existing research on 
international HE partnerships, which focus on high-level institutional actors or players, our case study focuses on the individuals involved in the initial stages of forming the partnership and the relationships at the heart of that process, which contributed to enlarging the network over the last fifteen years. This aligns with Koehn and Obamba's (2012) claim that "[m]any university partnerships initially emerge from and are built around personal networks" (360). These personal networks operate as forms of social capital, enabling (in this case) the early establishment of the CCUP. What our background account enabled us to see is the significance of fostering opportunities for the development of social capital through relationship building in the formation of HE partnerships. Existing research has shown the importance of the initial stages of partnership implementation. Arino and de la Torre (1998), for example, argue that no amount of relationship building can compensate for mistakes made during the initial establishment, framing, and launching of the partnership. Our social network mapping of the CCUP based on our interview data illustrates this point well and shows the role of social capital embedded in thick and strong relationships that enabled the initial formation and subsequent work of the CCUP.

\section{Social capital and solidarity}

As noted above, much of the existing literature focuses on the inherent structural imbalances embedded in North-South HE partnerships. Either explicitly or implicitly, critics have draws upon post-colonial theory to problematize the perpetuation of colonial inequalities through contemporary HE partnerships. Both Cuba and Canada are post-colonial societies although there has never been a colonizing relationship between the two. On the contrary, the relationship between the countries, over the past couple of centuries, has been characterized by mutuality and 
solidarity. Indeed, the strength of the relationships between CCUP members needs to be understood within the broader context of the long-standing human relationships between Cubans and Canadians dating back to the 17th century, which align with broader (and close) political and economic relations between the two countries. As Pagliccia (2014) argues, "the practice of solidarity involves establishing people-to-people relations that run parallel and are indeed akin to state-to-state foreign relations" (2). There is a long history of deep solidarity relations between the two countries beginning with Canadians volunteering to fight alongside Cubans against the Spanish during the Ten Years' War (1868-78) and the 1895-98 Cuban War of Independence (Kirk \& McKenna, 1997; Wylie, 2010). Strong relations continued to be built between Canadian and Cubans during the 20th century. A number of solidarity organizations emerged in both Canada and Cuba since the 1960s, which have promoted friendships between the two countries, and facilitated various solidarity tours and volunteer work brigades to Cuba (e.g. The Fair Play for Cuba Committees, the Cuban Institute of Friendship with the Peoples, Canadian Network on Cuba in Anglophone Canada, La Table de concertation de solidarité Quebec-Canada) (Pagliccia, 2014; Pierscionek, 2012; Wright, 2009).

Our interview data illustrates the significance of these kinds of solidarity initiatives in the formation of the CCUP with Canadian members such as Castor, Horton, and Torrino having been involved for many years (prior to the start of the partnership) in Cuban-Canadian solidarity initiatives. Castor reflected upon what motivated her to get involved with the partnership: "I did it because of my own political interest and my interest in social justice" (RCCan, 2015, personal communication). As she expressed, "I was a student radical in the 60 s right after the revolution 
and I always stayed in touch with politics in Cuba ... This is why I got involved in...I wanted to support the Cuban people and the Cuban revolution" (RCCan, 2015, personal communication). Torrino also talked about solidarity in the CCUP, explaining that "it is working alongside with

Cuban partners...it is a matter of sitting beside and in respect of their country's rights to selfdetermination and their right to trade with other countries on the world; and particularly, have academic cooperation" (JTCan, 2015, personal communication). Similarly, as Pagliccia (2008) in writing about Cuban-Canadian relations notes, solidarity "is directed at awareness of the condition and at social change or the redefinition of power relations" (121).

\section{Social Capital and Reciprocity}

Our findings revealed the economic benefits that emerged from the CCUP for the Cuban partners, illustrating the ways in which social capital can enable access to economic capital. As well, the ways in which the partnership enabled the accreditation of the CuU French program demonstrates the ways in which cultural capital can be increased through the enactment of social capital. However, above all, participants spoke most passionately about the shared goals and mutual benefits that stemmed from the partnership including collaborative research projects, crossborder teaching and conferences, as well as service learning. These are what Martins called “reciprocal gains" (SMCan, 2015, personal communication). Participants emphasized the mutual support of working together to improve the learning process of the language programs in both $\mathrm{CuU}$ and $\mathrm{CaU}$ sites. Moreover, the partnership not only generated research collaborations in teaching/learning languages, but also "collaborations to publishing articles between scholars from both universities... [such as] comparative studies between what is done in Canada and what is 
done in Cuba between scholars" (YHCub, 2015, personal communication). Additionally, the way the conference in Cuba has served as a platform for academics to engage in discussions about Canadian and Cuban history, culture, human rights and education has provided participants with reciprocal opportunities to better understand one another. Thus, through these reciprocal activities and initiatives, the experiences of Cuban and Canadian scholars contributed to "mutual enrichment and mutual learning" (YBCub, 2015, personal communication) and "experiences of learning from one another" (RGCub, 2015, personal communication).

Leng's (2016) study found that most partnership programs between Cambodian universities and their French, American and Japanese counterparts were based on mutuality where academics from both sides had already built close relationships based on strong personal ties with each other before moving to establish formal institutional agreements. Additionally, Tedrow and Mabokela's (2007) study about an academic partnership between a South African university and three international partners from the U.S, Canada and Europe demonstrates how the realization of objectives within partnerships is deeply affected by the relationships partner members have with one another and the mutual benefit each receives from the partnership. Similarly, our study also demonstrates the strong degree of reciprocity (i.e. mutual benefits) between the Canadian and Cuban participants built on the social capital inhering within the solidarity-based personal ties that predated the origins of the network and formed the foundation of the partnership. Furthermore, outlining the mutually beneficial initiatives and activities that characterize this partnership illustrates the flows and webs of interactions, based on strong connectivity and "communicative interaction" (Mische, 2003, 1) among the different actors of the partnership. Thus, the social 
capital embedded in the partnership relationships enable the participants to act together to achieve shared goals through mutually beneficial activities.

\section{CCUP: Strong and thick ties}

Scholarly networks, such as the CCUP, are constituted by relationships between individuals (nodes) connected through various activities. Our SNA approach allowed us to identify how the nodes in the network are connected to each other, their central or peripheral position and the strength of their links. As noted above, we consider social capital as being rooted in social networks of relatively stable relationships, characterized by trust, reciprocity and solidarity. The CCUP is such a network. Granovetter (1973) in his work on strong and weak ties in social networks asserts that the strength of a tie (or link) between actors in a network can be measured by the amount of time the link has been established, the degree of emotional intensity and intimacy, and reciprocal services. Social interactions among individuals create opportunities for knowledge sharing and information exchange, which are crucial in trust building. In his strength of weak ties theory, Granovetter (1973) posits that individuals obtain new and novel information from weak ties within that individual's group network. However, our study found that strong or thick ties between individuals in the CCUP were more important in the generation of trust and resulted in positive, mutually beneficial outcomes for network members. This aligns with the work of Levin and Cross (2004) who found that strong ties, more so than weak ties, enable the faster search for useful knowledge for improving performance in knowledge-intensive work.

Bourdieu (1986) argued that the amount of social capital an individual possesses depends on "the size of the network of connections he/she can effectively mobilize and on the volume of 
the capital (economic, cultural or symbolic) possessed in his/her own right by each of those to whom he/she is connected" (249). The fact that this network consisted initially in 1999 of 2-3 members and by 2015 had grown (from the grassroots up) to over 35 different members illustrates the ways in which network size enabled the production of social capital, contributing to the further production of mutually beneficial outcomes and activities. However, where we part ways with Bourdieu is with his focus on social capital existing within individuals. Our study demonstrates the ways in which social capital is embedded in a network based on common interests, solidarity, trust and reciprocity. Thus, social capital is an asset not so much for the individuals within the partnership, but for the CCUP as a whole. Through the social capital embedded in the relationships (ties, links) that constitute the partnership mutual benefits accrue to all.

\section{Role of Central Actors in the CCUP}

Our SNA mapping exercise sheds light on another key characteristic of this partnership: the role of the central actors of the network, who were identified by our interviewees as champions of the partnership. As central actors of the network (Crossley, et al., 2015), Pinero (VPCub) and Torrino (JTCan), demonstrated visionary leadership and orchestrated meaningful interconnectedness among all actors, building upon existing solidarity relations between and amongst the members. VPCub was central to the formation of the CCUP in engaging in initial conversations with CTCan regarding the mutual academic interests between the two universities. Her role facilitated the flow of information between the two universities, including a clear understanding of the purpose, benefits and scope of the partnership. VPCub also became central 
in connecting with numerous $\mathrm{CaU}$ professors, travelling many times to Canada since 2001 to foster support for the partnership.

On the Canadian side, while leadership was distributed amongst a number of Canadian participants, JTCan stands out as a champion of the network. He followed CTCan's suggestion of exploring with DHCan the opportunity to establish a partnership between the $\mathrm{CaU}$ and $\mathrm{CuU}$. In 2000, JTCan not only responded with Horton to Pinero's request of guiding the French language program in the $\mathrm{CuU}$, but he also attended the conference the following years, and initiated conversations with VPCub and the Vice Provost regarding other research collaborative projects. When Pinero came to Canada in 2001, Torrino introduced her to various CaU faculty members who became significant network actors. From then on, Torrino has been a central actor in supporting the teaching and research programs with faculty and students from both universities, as well as promoting the annual conference, creating and maintaining its website, and fostering connections amongst scholars across Canada, the U.S., and other countries.

Champions are key players in developing support and enthusiasm for networks. In our study, the relational interconnectedness and interdependence (Ferrier-Kerr \& Haxton, 2014) between Pinero, Torrino and the other members of the partnerships, built upon shared values and beliefs, resulted in mutually beneficial initiatives and opportunities for all in the network. Here we see social capital in action. Our findings align with other research that claims that the success of inter-university research networks and partnerships depends on having champions at each member university who are credible, informed and enthusiastic, as well as partners willing and able to promote the partnership at their institutions (Chapman et al., 2014; Webber \& Robertson, 2003). 
Thus, the social capital embedded in the "relationally-connected leadership style" (Ferrier-Kerr \& Haxton, 2014, 10) between Pinero and Torrino with other members of the network contributed to the successes of the CCUP partnership. The two central actors embodied the main roles in the creation, establishment, and development of the partnership and became third parties in exchanges and communication among the other actors in the network.

\section{Limitations and Conclusion}

Like other case studies, the main limitation of our study is the limited generalizability of our findings. However, we consider generalization as being made on a case-to-case basis. The value of case study research is in being able to use multiple sources of data and data collection methods to provide rich, in-depth and holistic understanding about our unit of analysis, the CCUP. In this respect, the value of case study is in "particularization, not generalization" (Stake, 1995, p. 7). Our instrumental case study provides evidence not only about this particular partnership, but also insight into the significance of fostering strong and sustainable relationships between members, especially within the context of north-south higher education partnerships.

Our methodological framework, SNA, coupled with social capital theory provided the tools to answer our research questions. Specifically, SNA enabled us to map out how individuals within the CCUP are connected, the nature of the ties and interconnections between the actors in the network, the strength and density of those bonds, including the 'thick' relationships between CCUP partners. SNA also offered us a lens to see the existence and role of champions on both 'sides' of the partnership who continue to be important actors in the partnership. Theorizing the 
connections of the actors in the network through social capital theory reveals the mutually beneficial outcomes that have arisen from the social capital embedded in the partnership relationships. Our research demonstrates the unique nature of the CCUP partnership in how it began and continues to grow, with ground-up relationships nurtured over many years, based on a long history of Canadian-Cuban solidarity relations. Our findings point to the fact that social engagement in and through networks is a pre-requisite for the accumulation and maintenance of social capital. Importantly, our study points to the need for policy-makers, administrators, managers and practitioners working in the higher education field to provide supports for individuals to develop and nurture relationships, based on common interests and reciprocity, with those in other settings as the foundation for mutually beneficial and sustainable partnerships. This is particularly important in terms of supporting North-South partnerships, which historically have been characterized by inequalities and dependencies. In contrast, the social capital stemming from a social network of strong and stable relationships in the CCUP, characterized by common values, trust and solidarity enabled positive reciprocal benefits for partners in both Cuba and Canada.

\section{References}

Abbasi, A., Wigand, R.T., Hossain, L. (2014) Measuring social capital through network analysis and its influence on individual performance. Library and Information Science Research, 36(1), 66-73.

Arino, A., \& de la Torre, J. (1998) Learning from failure: Towards an evolutionary model of collaborative ventures. Organization Science, 9, 306-325.

Assié-Lumumba, N. (2006) Higher education in Africa: Crisis, reforms and transformation. CODESRIA working paper. Dakar, Senegal: Council for the Development of Social Science Research in Africa. 
Association of Universities and Colleges of Canada (2005) Momentum: The 2005 Report on University Research and Knowledge Transfer, Ottawa: AUCC.

Borgatti, S. \& Halgin, D. (2011) 'On network theory', Organization Science, 22(5): 1168-1181.

Borgatti, S. P., Mehra, A., Brass, D. J., \& Labianca, G. (2009) 'Network analysis in the social sciences', Science, 323(5916): 892-895.

Bordogna, C. (2018) 'Transnational higher education partnerships and the role of operational faculty members: Developing an alternative theoretical approach for empirical research', Journal of Studies in International Education, 22(1): 3-19.

Bourdieu, P. (1986) The Forms of Capital. In Handbook of Theory of Research for the Sociology of Education, edited by J. E. Richardson. Oxford: Greenwood Press, 241-258.

Carnoy, M. (1974) Education as cultural imperialism. New York: David Mckay.

Chapman, D. W., Pekol, A. \& Wilson, E. (2014) 'Cross-border university networks as a development strategy: Lessons from three university networks focused on emerging pandemic threats', International Review of Education, 60: 619-637.

Coleman, J (1988) 'Social capital in the creation of human capital', American Journal of Sociology, 94, supplement: S95-S120.

Crossley, N., Bellotti, E., Edwards, G., Everett, M. G., Koskinen, J., \& Tranmer, M. (2015) Social network analysis for ego-nets. Thousand Oaks, CA: Sage.

Ferrier-Kerr, J. \& Haxton, P. (2014) 'Developing an inter-university partnership: The importance of relationally-connected leaders', The Journal of Values-Based Leadership, 7(2): 1-14.

Freeman, L.C. (1977) 'A set of measures of centrality based on betweenness', Sociometry, 40(1): $35-41$.

Granovetter, M. (1973) 'The strength of weak ties', American Journal of Sociology, 78(6): 13601380.

Jowi, J.O. (2009) 'Internationalization of higher education in Africa: Developments, emerging trends, issues and policy implications', Higher Education Policy, 22(3): 263-81.

Kim, J. \& Celis, S. (2016) 'Global partnership as a strategy for internationalisation: MBAs in Latin America and Asia and Oceania', Higher Education Policy 29(3): 355-378.

Kinser, K. \& Green, M. (2009) The Power of Partnerships: A transatlantic dialogue. Washington, DC: American Council on Education.

Kirk, J. M. \& McKenna, P. (1997) Canada-Cuba Relations: The Other Good Neighbor Policy. Gainesville: University Press of Florida.

Koehn, P.H. \& Obamba, M.O. (2012) 'Transnational Research and Development Partnerships in Higher Education: Global Perspectives', in D. Deardorff, H. de Wit, J. D. Heyl \& T. Adams (eds.) SAGE Handbook of International Education, Thousand Oaks, CA: Sage, 359-378.

Kot, C.F. (2016) 'The Perceived Benefits of International Partnerships in Africa: A Case Study of Two Public Universities in Tanzania and the Democratic Republic of Congo', Higher Education Policy, 29(1): 49-62.

Leng, P. (2016) 'Mutuality in Cambodian international university partnerships: looking beyond the global discourse', Higher Education, 72(3): 261-275.

Leng, P. \& Pan, J. (2013) 'The Issue of Mutuality in Canada-China Educational Collaboration', Canadian and International Education, 42(2): 1-15. 
Levin, D. Z., \& Cross, R. (2004). 'The strength of weak ties you can trust: The mediating role of trust in effective knowledge transfer', Management science, 50(11): 1477-1490.

Long, J.C., Cunningham, F., Carswell, P. \& Braithwaite, J. (2014) 'Patterns of collaboration in complex networks: the example of a translational research network', BMC Health Services Research, 14: 225.

Mische, A. (2003) 'Cross-talk in movements: Reconceiving the culture-network link', in M. Diani \& D. McAdam (eds.), Social movements and networks: Relational approaches to collective action, Oxford: Oxford Scholarship Online: 258-80.

Morfit, C., Gore, J. \& Akridge, P.B. (2009) U.S. Higher Education Partnerships in Africa: 19972007, Washington DC: USAID and Higher Education of Development.

Mützel, S. (2009) 'Networks as culturally constituted processes: a comparison of relational sociology and actor-network theory', Current Sociology, 57(6): 871-887.

Obamba, M.O. and Mwema, J.K. (2009) 'Symmetry and asymmetry: new contours, paradigms, and politics in African academic partnerships', Higher Education Policy 22(3): 349-371.

Pagliccia, N. (2008) 'Solidarity Organizations and Friendship Groups: Internationalist Volunteer Work Brigades and People-to-People Ties', in A. Kapacia \& A. I. Gray (eds.) The Changing Dynamic of Cuban Civil Society, Gainsville: University Press of Florida.

Pagglicia, N. (2014) Introduction: Solidarity-Based People-to-People Foreign Relations" in N. Pagliccia \& J. Kirk, (Eds). Cuba Solidarity in Canada: Five Decades of People-to-People Foreign Relations (pp. 1-30). Victoria: Friesen Press.

Pierscionek, T. (2012) The Cuban Institute for Friendship with the People. London Progressive Journal, Available at http://londonprogressivejournal.com/article/view/1138/the-cubaninstitute-for-friendship-with-the-peoples

Pinheiro, C. (2011) Social network analysis in telecommunications. Hoboken, NJ: John Wiley and Sons.

Putnam, R. D. (1995) 'Tuning in, tuning out: The strange disappearance of social capital in America.' Political Science and Politics, 28(4): 664-683.

Scott, J., \& Carrington, P. J. (Eds.) (2011) The Sage handbook of social network analysis. Thousand Oaks, CA: Sage.

Singh, M. (2010) 'Re-orienting internationalisation in African higher education', Globalisation, Societies and Education, 8 (2): 269-282

Stake, R. (1995) The art of case study research. Thousand Oaks, CA: Sage Publications.

Sutton, S. B., Egginton, E., \& Favela, R. (2012) 'Collaborating on the Future: Strategic Partnerships and Linkages', in Deardorff, D., de Wit, H., Heyl, J.D. \& Adams, T. (Eds.) Sage Handbook on International Higher Education. Thousand Oaks, CA: Sage, pp. 147-165.

Tedrow, B.J. \& Mabokela, R.O. (2007) 'An analysis of international partnership programs: The case of an historically disadvantaged institution in South Africa', Higher Education, 54(2), 159-179.

Teferra, D. (2009) 'African research collaboration must be fair and equal', Available at http://www.scidev.net/global/policy/opinion/african-research-collaborations-must-be-fairand-e.html 
Times Higher Education (2016) World University Rankings 2016-2017 Methodology. Available at https://www.timeshighereducation.com/world-university-rankings/methodology-worlduniversity-rankings-2016-2017

Wagner, C., \& Leydesdorff, L. (2005) Network structure, self-organization, and the growth of international collaboration in science. Research Policy, 34(10): 1608-1618.

Webber, C. F., \& Robertson, J. M. (2003) 'Developing an international partnership for tomorrow's educational leaders', International Studies in Educational Administration, 31(1): 15-32.

Wright, C. (2009) 'Between Nation and Empire: The Fair Play for Cuba Committees and the Making of Canada-Cuba Solidarity in the Early 1960s', in R. Wright \& L. Wylie (eds.) Our Place in the Sun: Canada and Cuba in the Castro Era, Toronto: University of Toronto Press, pp. $96-120$

Wylie, L. (2010) Perceptions of Cuba: Canadian and American Policies in Comparative Perspective. Toronto: University of Toronto Press.

Yeh, L. \&. Chang, F. (2016) 'Strategic Alliance of EMBA International Programs in Universities in Taiwan and China', Xuexioa Xingzheng Shuangyuekan [School Administrators], 104: 82101. 